3. Yoder, J. I. Planta 202, 407-413 (1997).

4. Karban, R., Baldwin, I. T., Baxter, K. J., Laue, G. \& Felton, G. W. Oecologia 125, 66-71 (2000)

5. Keeley, J. E. \& Fotheringham, C. J. Science 276, 1248-1251 (1997).

6. Davis, M. H. \& Simmons, S. R. Plant Cell Environ. 17, 829-836 (1994).

7. Falik, O., Reides, P., Gersani, M. \& Novoplansky, A. J. Ecol. 91, 525-531 (2003).

8. Mahall, B. E. \& Callaway, R. M. Am. J. Bot. 83, 83-98 (1996).
9. Hess, L. \& De Kroon, H. J. Ecol. 95, 241-251 (2007).

10. Hamilton, W. D. J. Theor. Biol. 7, 1-16 (1964)

11. Gersani, M., Brown, J. S., O'Brien, E. E., Maina, G. M. \& Abramsky, Z. J. Ecol. 89, 660-669 (2001).

12. Donohue, K. Am. Nat. 162, 77-92 (2003).

13. Schenck, J., Mahall, B. E. \& Callaway, R. M. Adv. Ecol. 28, 145-180 (1999).

14. Hiscock, S. J., Bown, D., Gurr, S. J. \& Dickinson, H. G. Sex. Plant Reprod. 15, 65-74 (2002).

15. Holzapfel, C. \& Alpert, P. Oecologia 134, 72-77 (2003).

\title{
NEUROPHYSIOLOGY
}

\section{Channelling cold reception}

\section{Bernd Nilius and Thomas Voets}

\section{Perception of cold and hot is one of life's essentials. Three research teams find that, when a temperature-sensing receptor is deleted in mice, the animals lose their response to a range of cold temperatures.}

In his description of the five senses, Aristotle described visus (sight) as the most supreme sense, yielding the highest pleasure, and contactus (touch and sensing temperature) as the most rudimentary sense, required for sheer survival ${ }^{1}$. Indeed, to maintain a healthy core body temperature of $37{ }^{\circ} \mathrm{C}$, humans - like other animals that can retain a relatively constant internal body temperature - need to be able to 'feel' the ambient temperature and show a suitable physiological or behavioural response to drastic fluctuations in it.

Ambient temperatures are sensed by cells of the peripheral nervous system, which convey thermal information from the skin and peripheral tissues to the brain (for reviews see refs 2,3 ). Three papers ${ }^{4-6}$, including one by Bautista et al. in this issue, now report the consequences of deleting the gene encoding a peripheral cold sensor called TRPM8. These researchers find that mice that do not have the TRPM8 cation channel - a member of the transient receptor potential (TRP) family - have severe deficiencies in sensing cold and in cold-induced behaviour.

It is not surprising that the deletion of the TRPM8 gene leads to reduced cold sensitivity. Previous studies had shown that TRPM8 is a temperature-sensitive TRP channel that is activated by moderate cooling and by 'cool' substances such as menthol, eucalyptol and icilin $^{3}$. It is expressed in the free nerve endings of a subset of small-diameter sensory neurons ${ }^{7}$; the nerve fibres of these neurons, which are not covered by the myelin sheath, carry sensory information from the skin to the brain (Fig. 1a). Consequently, TRPM8 had been proposed as the source of non-painful and painful reactions to cold ${ }^{3}$ and as the molecular mediator of cold-induced pain relief ${ }^{8}$.

The results of studies ${ }^{4-6}$ on TRPM8deficient mice mainly endorse these earlier views. At a cellular level, all three studies ${ }^{4-6}$ showed that sensory neurons of these mice show a drastically blunted response to cold stimuli - for example, a drop in temperature from around $30{ }^{\circ} \mathrm{C}$ to below $20^{\circ} \mathrm{C}-$ and to menthol. Behavioural studies ${ }^{4-6}$ illustrate the consequences of such severe deficits in cold sensation. When given the freedom of choice, mice with their TRPM8 gene intact prefer to reside in a warm (around $30^{\circ} \mathrm{C}$ ) rather than a $\operatorname{cool}\left(20^{\circ} \mathrm{C}\right.$ or lower $)$ zone. By contrast, those without TRPM8 do not discriminate against cool temperatures, cheerfully walking into the cold. Moreover, these mice no longer exhibit the typical 'wet-dog-shake' response to injections of icilin, and show a reduced sensitivity to extreme and painful cold stimuli. Finally, Colburn et al. ${ }^{4}$ find that TRPM8 might participate in hypersensitivity to cold, which is observed after inflammation or nerve injury ${ }^{9}$.

So, do these studies fully elucidate the mechanism of cold sensing? Not really. First, all three papers ${ }^{4-6}$ equivocally report the existence of a fraction of neurons in the TRPM8-deficient mice that still respond to cold. These neurons have a low temperature threshold for activation by cold $\left(12{ }^{\circ} \mathrm{C}\right.$ compared with around $22{ }^{\circ} \mathrm{C}$ for TRPM8containing neurons) ${ }^{6}$, and so they might be important for noxious cold sensing. The debate about whether the remaining cold sensitivity is mediated by another TRP channel, TRPA1 (ref. 3), is ongoing, and analysis of mice lacking both TRPM8 and TRPA1 should eventually settle this. Furthermore, another recent study ${ }^{10}$ reports that a non-TRP channel - the voltage-dependent sodium channel $\mathrm{Na}_{\mathrm{v}} 1.8$ - is a candidate sensor of very low temperatures.

These observations on TRPM8-deficient mice ${ }^{4-6}$ also prompt a look back at neurophysiological results on the fundamental basis of temperature sensation published in the early 1950s. Hensel and Zotterman ${ }^{11}$ reported the temperature dependence of cutaneous $\mathrm{C}$ and

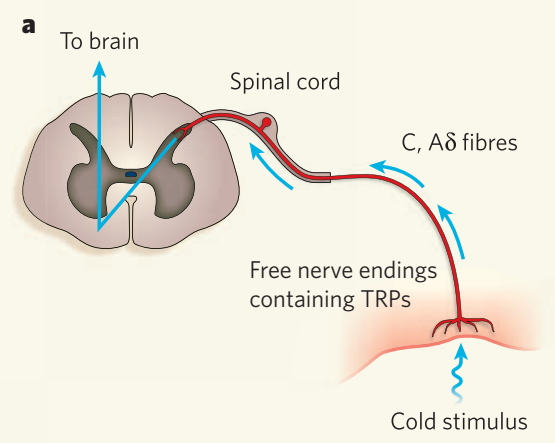

b
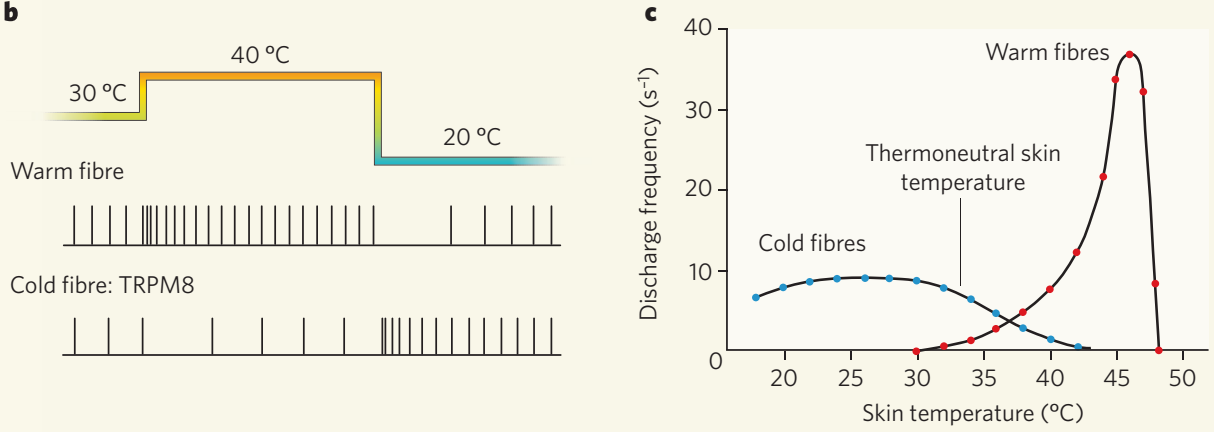

Figure 1 | Sensing cold. Three studies ${ }^{4-6}$ implicate the TRPM8 cation channel in cold perception. a, Stimulation of TRPM8 in free nerve endings of $C$ and $A \delta$ fibres leads to the repetitive discharge of action potentials. These signals propagate into the dorsal root of the spinal cord, and stimulate neurons that transmit thermal information to the brain. $\mathbf{b}$, Stepwise changes in temperature evoke mirror responses in warm and cold fibres. Warm fibres expressing heat-activated, temperature-sensitive TRPs respond to sudden heating with a transient increase in the discharge frequency of action potentials (on-response), whereas sudden cooling leads to a transient decrease in frequency (off-response). Cold fibres expressing the TRPM8 channel show an opposite reaction - an off-response to heating and an on-response to cooling. c, Steady-state discharge rates of cold and warm fibres. Note that the same steady-state discharge rate can occur at two different temperatures in a single fibre, raising the question of how the sensation of different temperatures is decoded. 


\section{TOXICOLOGY \\ Danger in the diet}

Visit websites selling homeopathic
remedies, and sooner or later you
will find the virtues of extracts of
Aristolochia clematitis extolled. The
dark side of this plant's biochemical
products is examined by Arthur
Grollman, Bojan Jelaković and
colleagues in Proceedings of the
National Academy of Sciences
(A.P. Grollman et al. Proc. Natl
Acad. Sci. USA doi:10.1073/
pnas.0701248104). They provide
a strong case that the aristolochic
acid produced by A. clematitis is
the cause of endemic (Balkan)
nephropathy.
This disease results in kidney
failure and is associated with cancer
of the upper urinary tract. Its name
stems from its incidence in farming
communities along tributaries of the
Danube. Here, as Grollman
et al. confirmed in their early work
done in Croatia, the plant grows
in wheat fields and its seeds
become mixed with wheat grains

during harvesting - and so can contaminate the flour that is subsequently baked into bread.

The authors' investigations were prompted by similarities between endemic nephropathy and a condition called aristolochic acid nephropathy, which was identified in a group of women in Belgium and attributed to their use of herbal products as part of a slimming regime. Aristolochic acid reacts with DNA, and forms tell-tale biomarkers that can be used as indicators of exposure to the substance.

These biomarkers indeed turned out to be present in Croatian patients with endemic nephropathy, and malignancies of the upper urinary tract, who had long inhabited villages likely to be subject to dietary contamination. They were not seen in patients with other types of kidney disease.

Grollman et al. then went further, delving into the mutational background of the cancers. They focused on the tumoursuppressor protein $\mathrm{p} 53$, which helps protect the genome against damage. Here they identified a large proportion of switches of the adenine-thymine nucleotide coupling in DNA to thymine-adenine. This mutational 'fingerprint' is also seen in cultured cells and in rodents treated with aristolochic acid. All in all, the authors' detective work provides enough evidence to put A. clematitis in the dock, if not to allow an outright conviction.

Other causes of endemic nephropathy have been considered over the years, including one that echoes the notorious case of ergotism. This disorder was eventually attributed to the action of toxins produced by fungal infection of cereals. A fungal toxin, ochratoxin $A$, has likewise been proposed as the agent behind endemic nephropathy, but the authors find the case for that
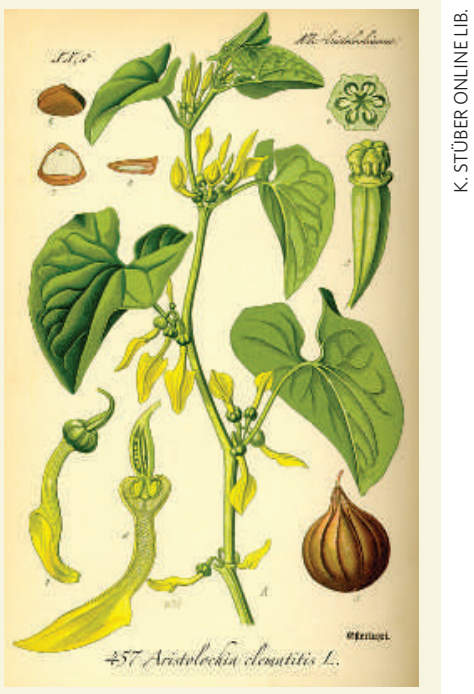

to be weak. However, they estimate that only about 1 in 20 people exposed to high levels of aristolochic acid develop overt disease. They conclude, then, that there must be a large genetic component to susceptibility, and investigations of that aspect will shortly be under way.

Tim Lincoln
A $\delta$ fibres, which are part of specific thermosensor neurons present in nearly all vertebrates, but are especially important in mammals (Fig. 1a). These classic studies showed that neurons containing cold receptors ( $\mathrm{C}$ and $\mathrm{A} \delta$ fibres) or warm receptors (mainly $\mathrm{C}$ fibres) exhibit a static discharge frequency of action potentials. In neurons containing warm receptors, the discharge frequency increases steeply when the temperature rises from $30^{\circ} \mathrm{C}$ to $43^{\circ} \mathrm{C}$ and then falls off at higher temperatures; in those with cold receptors, the discharge frequency rises as temperature drops from $40{ }^{\circ} \mathrm{C}$ to around $25^{\circ} \mathrm{C}$, and then decreases to a stationary frequency (Fig. 1c).

Based on the input from both cold and warm fibres, the central nervous system somehow identifies temperatures below the thermoneutral skin temperature of about $33^{\circ} \mathrm{C}$ as cold, and temperatures above this as warm. An outstanding question is how the static discharge pattern relates to the activity of TRPM8 and other temperature-sensitive TRPs. Bautista and colleagues ${ }^{6}$ provide some insights from recordings of cutaneous $\mathrm{C}$ and $\mathrm{A} \delta$ fibres.

Usually, gradual cooling of cold-sensitive $\mathrm{C}$ fibres from $35^{\circ} \mathrm{C}$ to $2{ }^{\circ} \mathrm{C}$ activates a burst of action potentials, with the fibres eventually adopting a residual firing rate. In mice without TRPM8, the activation phase is absent, but the residual firing is preserved. This indicates that cold-induced activation and subsequent desensitization of TRPM8 underlie the transient discharge pattern that occurs on cooling.
The instantaneous responses of warm and cold receptors to temperature are mirror images of one another. Warm receptors exhibit an onresponse (increase in discharge frequency) on heating, and an off-response on cooling; the opposite is true for cold receptors (Fig. 1b). This implies that cooling evokes a dual message to the brain: an increased activity of cold-sensitive fibres and a decreased activity of warmsensitive fibres. It might also explain the classical psychophysiological observations in Ernst Weber's 'three-bowl experiment', also called Weber's illusion ${ }^{12}$ : coming from a bowl with cold water, water at neutral temperature feels warm; coming from a bowl with warm water, the same neutral temperature is perceived as cold.

Through single nerve-fibre recordings, Bautista et al. ${ }^{6}$ found that part of the onresponse of cold receptors to a cold stimulus is due to TRPM8 activation. However, whether the off-response of these TRPM8-expressing cold fibres contributes to warm perception, or whether the closing of heat-activated thermoTRPs contributes to a cold response, remains unclear.

A further crucial difference between cold and warm sensations is illustrated by another warm receptor - TRPV3. This receptor is expressed in the keratinocyte cells of the skin, which pass the signal to the sensory neurons through an unidentified messenger system ${ }^{13}$. Can such an indirect mechanism of nerve-fibre activation in response to cold also be relevant to TRPM8?

Aristotle appreciated the basic importance of thermosensation for survival. It is curious, however, that these studies ${ }^{4-6}$ did not look into the consequences of loss of cold sensitivity on thermoregulation and core temperature. A lower core temperature may even increase the lifespan ${ }^{14}$, so the cold-indifferent TRPM8deficient mice might live longer than their cold-fearing normal mates. Nonetheless, these studies re-ignite the excitement about TRPs once again.

Bernd Nilius and Thomas Voets are in the Department of Molecular Cell Biology, Division of Physiology, Campus Gasthuisberg, KU Leuven, Herestraat 49, B-3000 Leuven, Belgium. e-mail: bernd.nilius@med.kuleuven.be

1. Bernstein, J. Die fünf Sinne des Menschen (Brockhaus, Leipzig, 1875)

2. Voets, T., Talavera, K., Owsianik, G. \& Nilius, B. Nature Chem. Biol. 1, 85-92 (2005).

3. Dhaka, A., Viswanath, V. \& Patapoutian, A. Annu. Rev. Neurosci. 29, 135-161 (2006).

4. Colburn, R. W. et al. Neuron 54,379-386 (2007).

5. Dhaka, A. et al. Neuron 54, 371-378 (2007)

6. Bautista, D. M. et al. Nature 448, 204-208 (2007)

7. McKemy, D. D., Neuhausser, W. M. \& Julius, D. Nature 416 52-58 (2002).

8. Proudfoot, C. J. et al. Curr. Biol. 16, 1591-1605 (2006).

9. Chung, M. K. \& Caterina, M. J. Neuron 54, 345-347 (2007)

10. Zimmermann, K. et al. Nature 447, 856-859 (2007).

11. Hensel, H. \& Zotterman, Y. J. Neurophysiol. 14, 377-385 (1951)

12. Schmidt, R. F. \& Thews, G. Physiologie des Menschen 214-217 (Springer, Heidelberg, 1990).

13. Lee, H. \& Caterina, M. J. Pflügers Arch. Eur. J. Physiol. 451, 160-167 (2005)

14. Conti, B. et al. Science 314, 825-828 (2006). 